\title{
ULTRASONIC NONDESTRUCTIVE MATERIALS CHARACTERIZATION
}

\author{
Robert E. Green, Jr. \\ The Johns Hopkins University \\ Baltimore, Maryland 21218
}

\begin{abstract}
A brief review of ultrasonic wave propagation in solid materials is presented with consideration of the altered behavior in anisotropic and noninear elastic materials in comparison with isotropic and Iinear elastic materials. Some experimental results will be described in which ultrasonic velocity and attenuation measurements give insight into materials microstructure and associated mechanical properties. Recent developments with laser beam non-contact generation and detection of ultrasound will be presented. The results of several years of experimental measurements using high-power ultrasound will be discussed, which provide substantial evidence of the inability of presently accepted theories to fully explain the interaction of ultrasound with solid materials. Finally, a special synchrotron x-ray topographic system will be described which affords the possibility of observing direct interaction of ultrasonic waves with the microstructural features of real crystalline solid materials for the first time.
\end{abstract}

\section{INTRODUCTION}

Although historically nondestructive techniques have been used almost exclusively for detection of macroscopic defects in structures after they have been in service for some time, it has become increasingly evident that it is both practical and cost effective to expand the role of nondestructive evaluation to include all aspects of materials production and application. Currently efforts are directed at developing and perfecting nondestructive evaluation techniques which are capable of monitoring and controliing the materials production process; the materials stability during transport, storage, and fabrication; and the amount and rate of degradation during the materials inservice life. Ultrasonic techniques afford very useful and versatile nondestructive methods for evaluating the microstructures, associated mechanical properties, and macroscopic flaws in solid materials.

\section{ULTRASONIC WAVES IN SOLID MATERIALS}

The use of ultrasonic waves as nondestructive probes has as a prerequisite the careful documentation of the propagational characteristics of the ultrasonic waves themselves ( $r$ ef. 1). Since in nondestructive evaluation applications it is not desirable for the ultrasonic waves to alter the material through which they pass, it is necessary to work with very low amplitude waves, which normally are regarded to obey linear elasticity theory. Although most practical uses of ultrasonics are applied to solid materials which are polycrystalline aggregates 
and therefore assumed to be isotropic, with real crystalline solids the condition of ideal isotropy is extremely difficult if not impossible to attain. The prime reason for this is that the solidification or forming and heating processes associated with material processing does not permit a random distribution of crystallographic orientations among the aggregation of grains and often does not even permit a uniformity of grain size. Therefore, most real polycrystalline aggregates possess a "texture" and this texture strongly influences the mechanical properties of the anisotropic material including ultrasonic wave propagation.

\section{LINEAR ELASTIC WAVE PROPAGATION}

In general three different linear elastic waves may propagate along any given direction in an anisotropic material. These three waves are usually not pure modes since each wave generally has particle displacement components both parallel and perpendicular to the wave normal. However, one of these components is usually much larger than the other; the wave with a large parallel component is called quasi-longitudinal while the waves with a large perpendicular component are called quasi-shear. In the event that sufficient symmetry prevails such that the direction of propagation is elastically isotropic or if the material is elastically isotropic in general, then all modes become pure modes, i.e. the particle displacements are either parallel or perpendicular to the wave normal, and the two quasi-shear modes degenerate into one pure shear mode. Also of great practical importance to elastic wave propagation in anisotropic materials is the fact that the direction of the flow of energy per unit time per unit area, the energy-flux vector, does not in general coincide with the wave normal as it does in the isotropic case, i.e. the ultrasonic beam exhibits refraction even for normal incidence.

Figure 1 serves to illustrate several aspects of ultrasonic wave propagation in anisotropic materials. This figure is one of a set of four photographs originally published by Merkulov and Yakovlev (ref. 2) who used the optical schlieren technique to visualize the sound field due to ultrasonic waves propagating in optically transparent quartz crystals. In Fig. 1 a single $25 \mathrm{MHz}$ $x$-cut quartz piezoelectric transducer attached to a $y$-face of a single crystal quartz block is shown to simultaneously generate a quasi-longitudinal and a quasi-shear wave, both of which exhibit energy-flux deviation from the wave normal, i.e. refraction. In general, a piezoelectric transducer generates both longitudinal and shear waves, but depending on the particular piezoelectric properties of the specific transducer one type of mode will be dominant. It should be noted, that since most real structural materials exhibit some degree of anisotropy, great care must be exercised in locating flaws in these materials using ultrasonic techniques. For example, Fig. 2 illustrates schematically how anisotropy caused by the strong materials texture of the test object results in a marked deviation of the energy-flux (the ultrasonic beam) such that it detects a crack which is not in the direct line of sight beneath the transducer. If the degree of energy-flux deviation was not determined prior to this test and the assumption was made that no deviation occurred, subsequent investigation would not reveal the crack in the calculated position beneath the transducer, while the real crack location would not be confirmed. 
Here is a good place to call attention to the fact that, although many duthors and investigators draw a close analogy between electromagnet1c wave propagation and elastic wave propagation in solid materials, great caution should be exercised in doing so. The behavior of anisotropic materlals with respect to propagation of elastic waves is much more complicated than the propagation of electromagnetic waves, since the materlal constitutive equations required to properly descrlbe elastio waves are of higher order tensor rank than those required to describe electromagnetic waves ( $r$ ef. 3 ).

\section{ATTENUATION OF NEARLY LINEAR ELASTIC WAVES}

For all read solids, the assumption of pure linear elastiolty is only an approximation since all real ultrasonic waves are attenuated as they propagate. If one considers this more realistic case, one finds, to the lowest order of approximation, that the general propagational characteristics of such waves in solid materials are ldentical with the linear elastic case considered previously, as regards wave speeds, particle displacements, energy flux vectors, and diffraction spread. However, as a result of various mechanisms, there will be energy loss from these propagating waves.

Although geometrical effects can cause energy to be lost from the ultrasonic beam, such losses are not indicative of intrinsic loss mechanisms associated with the microstructure. Once proper precautions are taken to either eliminate or control these geometrical effects, ultrasonic attenuation measurements serve as a very sensitive indicator of internal loss mechanisms caused by microstructures and microstructural alterations in the material (ref. 4). This sensitivity derives from the ability of ultrasonic waves to interact with volume defects such as cracks, mlorocracks, included particles, and precipitates; surface defects such as grain boundaries, interphase boundarles, and magnetic domain walls; and dislocation line defects. Moreover, ultrasonic waves are sensitive to the interaction of point defects such as impurity atoms and vacancies with dislocations.

Since a nearly linear elastic wave propagating in a crystal has a stress field represented by a second-order tensor, and since dislocation motion in crystals is primarily confined to certain directions in specific planes, the interaction of ultrasonic waves with dislocations in single crystals is anisotropic. Calculation of the stress on the dislocations is obtained by resolving the nine components of stress associated with the elastic wave into the appropriate slip direction and then summing.

Figure 3, taken from the work of Swanson and Green (ref. 5), illustrates the experimental agreement with the orientation dependence of ultrasonic attenuation caused by dislocation damping and also exhibits the extreme sensitivity of such ultrasonic waves as probes to measure plastic deformation. The data to plot the curves shown in this figure was obtained by measuring the change of attenuation of specifically polarized shear waves propagating along the axis of two similar cylindrical aluminum crystals while the orystals were subjected to uniaxial compressive deformation. Figure $3(a)$ shows the stress-strain curve and the change in attenuation-strain curve for a quasi-transverse wave polarized with a large component of particle displacement 
perpendicular to the projection of the primary-slip direction onto the end surface of the crystal specimen. With such a polarization, there is only a very small interaction between the stress field of the ultrasonic wave and dislocations on the primary-slip system. As can be seen, the attenuation rises steadily as the specimen is loaded to the yield point. During easy glide of the dislocations, the attenuation remains relatively constant, but starts to increase again as other slip systems become active.

Figure $3(\mathrm{~b})$ shows the stress-strain curve and the change in attenuation-strain curve for a quasi-transverse wave polarized with a large component of particle displacement parallel to the projection of the primary-slip direction onto the end surface of the crystal specimen. With such a polarization, there is a maximum interaction between the stress field of the ultrasonic wave and dislocations on the primary-slip system. In this case, the attenuation increased with increasing strain up to the yield point at which time there was a sharp decrease. After the sudden decrease associated with the yield point the attenuation continued to increase with increasing strain. These results show that ultrasonic attenuation measurements are extremely orientation dependent and that such measurements are much more sensitive to the early stages of plastic deformation than are conventional stress-strain measurements.

Sachse and Green, (ref. 6), conducted additional experiments which illustrate the extreme sensitivity of ultrasonic attenuation measurements to microstructural alterations. Figure 4 shows the results of an experiment in which an aluminum crystal, which had previously been loaded to a plastic load of $180 \mathrm{~kg}$, was reloaded to $60 \mathrm{~kg}$ and maintained at this load for one minute, unloaded to $45 \mathrm{~kg}$ and maintained for one minute, unloaded to $30 \mathrm{~kg}$ and maintained for one minute, unloaded to $15 \mathrm{~kg}$ and maintained for one minute, and then unloaded completely. Upon subsequent reloadirg to $70 \mathrm{~kg}$ and unloading, the ultrasonic attenuation displayed dips at those load values which had been maintained for a short time during the previous cycle. Note that even though the attenuation "remembered" the discontinuous nature of the first load-unload cycle, the load-unload curve (or equivalently the stress-strain curve) gave no indication of it. The observed results were attributed to the pinning of dislocation loops by point defects which were preferentially located at the position they occupled when the load was maintained constant for the one minute intervals. Upon reloading, these point defects pinned the dislocation loops again when the dislocations arrived at the location of the defects thus causing the dips in attenuation. These results show that ultrasonic attenuation measurements are sensitive to migration of point defects and their interaction with dislocations.

Figure 5 demonstrates the ability of ultrasonic attenuation measurements to detect extremely small microstructural alterations during fatigue testing and hence give early warning of fatigue-induced failure. This figure was taken from the work of Joshi and Green (ref. 7) who used ultrasonic attenuation measurements as a continuous monitor of fatigue damage in cold-rolled 1015 polycrystalline steel specimens which were cycled in reverse bending as cantilever beams to fracture at $30 \mathrm{~Hz}$. Note that the ultrasonic attenuation change indicated microstructural alterations, probably microcrack formation, prior to detection of an additional ultrasonic pulse on the A-scan display as is used in conventional nondestructive ultrasonic evaluation to detect crack formation. 


\section{NONLINEAR ELASTIC WAVE PROPAGATION}

Nonlinear effects associated with ultrasonic wave propagation may also be used to advantage for nondestructive materials characterization (ref. 1). These nonlinear effects may arise from several causes. First, the ultrasonic wave amplitude may be sufficiently large so that finite strains arise. Second, a material may behave in a nonlinear fashion, even when very low amplitude ultrasonic waves are propagated, provided that a sufficient amount of external stress is superimposed or provided that a residual stress (strain) is present in the material.

Although $x$-ray diffraction techniques have historically been the nondestructive method most often used in actual practice to measure residual stress (strain), they are not optimally suited for field applications partially because the necessary equipment is heavy and bulky and, perhaps more importantly, they suffer from the fact that they only serve to determine the state of stress (strain) in a surface layer of a material, while in many practical cases a knowledge of the bulk stresses (strains) is desired. Ultrasonic residual stress (strain) measurements have been made far less frequently, probably because of lack of familiarity with nonlinear elasticity theory and the experimental techniques necessary to obtain the required ultrasonic velocity measurement accuracy.

Most ultrasonic measurements of residual stress (strain) have been based on stress induced acoustical birefringence of a homogeneous isotropic solid. When linear elastic shear (transverse) waves are propagated through a homogeneous isotropic solid at right angles to the direction of applied or residual stress, the shear wave with particle displacement parallel to the direction of the stress propagates with a faster velocity than the shear wave with particle displacement perpendicular to the direction of the stress. Other ultrasonic techniques can also be used to make such measurements. For example, five of the equations derived originally by Hughes and Kelly (ref. 8) relate a linear elastic wave velocity to a stress component in the material. These equations can be used either singly or in appropriate combination to determine stress components from experimental measurements of various ultrasonic wave velocities. Moreover, additional features of nonlinear elastic wave propagation, such as harmonic generation, temperature dependence of ultrasonic velocity, change in velocity as a function of applied magnetic field, or ultrasonic wave dispersion, have been proposed for residual stress determinations. Details of most of these measurement techniques, as well as a survey of theoretical considerations, may be found in two recent review articles (refs. 9 and 10 ).

The major difficulty associated with reliable (strain) measurement is that the change in linear

ultrasonic residual stress elastic wave velocities in solid materials due to residual stress is small and other factors, which can cause greater velocity changes, may mask residual stress effects. The prime factor in this regard is the fact that all real structural materials are initially anisotropic and not isotropic. Therefore, the ultrasonic residual stress (strain) measurement problem becomes one of measuring changes in anisotropy before and after stressing rather than the commonly treated theoretical problem of stress-induced anisotropy of an originally isotropic solids. 
Additional problems arise with ultrasonic wave propagation in inhomogeneous materials. The presence of a single bounding surface complicates the propagational characteristics of ultrasonic waves in solid materials and can lead to erroneous interpretation of velocity and attenuation measurements. The presence of many bounding surfaces, such as may occur in composites, complicates the propagational characteristics even more and, except in a few special cases, the problems have not been solved analytically. However, solution of these problems will permit proper ultrasonic measurements to be an invaluable tool in characterizing composite materials.

\section{CONTACT OR WATER COUPLED TRANSDUCERS}

Historically, piezoelectric crystals such as quartz were predominantly used as transducer materials. Currently, poled ferroelectric ceramics are most of ten used. Depending on the particular cut (crystallographic orientation) of the piezoelectric crystal or the particular geometry and poling configuration of the ferroelectric ceramic, the active elements may vibrate so as to generate longitudinal, shear, surface, or a variety of different guided wave modes. A number of shaped piezoelectric elements and electrode configurations have been developed in order to cause the generated ultrasonic beam to have the profile desired such as straight or focused. Unless these special precautions are taken, the ultrasonic beam generated will experience diffraction spread which increases with increasing distance from the transducer and is a function of transducer diameter and ultrasound wavelength. Figure 6 serves to illustrate the fact that even though this diffraction spread may only be moderate in an isotropic material, it can be quite pronounced in anisotropic material. In this figure, taken from the work of Liu (ref. 11), the diffraction spread of $10 \mathrm{MHz}$ longitudinal waves in quartz were measured experimentally using a laser scan technique. The half-width of the ultrasonic beam is plotted as a function of the distance from the piezoelectric transducer, indicated by cross-hatching at the top of the figure. It should be noted that the diffraction spreads for the case of elastically isotropic fused quartz and the elastically isotropic z-axis direction in a quartz crystal are the same within the limits of the experimental parameters used, while the diffraction spread for the case of wave propagation along the anisotropic $x$-axis direction in the quartz crystal is much greater. This illustrates once more the importance of properly considering the effects due to anisotropy of real materials and makes questionable the commonly used method of determining ultrasonic transducer beam profiles using a tank of water as the propagation medium.

A major problem associated with conventional ultrasonic techniques is the requirement that either the generating and receiving transducers be acoustically bonded to the test structure with some sort of acoustical impedance matching coupling medium such as water, oll, or grease; or often more harmful, particularly to polymer based composite materials, is the necessity of immersing the entire structure to be tested in a tank of water or coupling the transducers to the workpiece using water squirter systems. Although the couplant allows acoustical energy to propagate into the structure, it causes several problems in addition to potential harm to the test object. For velocity measurements the 
coupling medium can cause transit time errors on the order of one percent of the measured values. Due to partial transmission and partial reflection of sound energy in the couplant layer, there may be a change of shape of the waveform which can further affect velocity measurement accuracy. This can also lead to serious errors in absolute attenuation measurements of up to twenty percent of the measured values. This latter fact is the reason that so few rellable absolute measurements of attenuation are reported in the scientific literature. The requirement of physical contact between transducer and test structure places limitations on ultrasonic testing in structural configurations which possess geometries with difficult to reach areas. Limitations are also placed on the testing of materials at elevated temperatures or in the environment of outer space.

\section{NON-CONTACT TRANSDUCERS}

A method of non-contact generation and detection of ultrasound is therefore of great practical importance. Several such techniques are presently available in various stages of development, namely capacitive pick-ups, electromagnetic acoustic transducers (EMAT'S), and laser beam optical generators and detectors. However, as the name implies, capacitive pick-ups cannot be used as ultrasonic generators and, even when used as detectors, the air gap required between the pick-up and test structure surface is extremely small, which in essence causes the device to be very nearly a contact one. EMAT'S, on the other hand, have already been successfully used for material defect characterization particularly in metal bars, tubes, pipes, and plates. They have also been used for material property measurement such as material anisotropy (texture) and internal stress (strain) state. As useful as these devices have proven, they still have not been optimized because they are very inefficient ultrasound generators and require very large power supplies in order to operate properly. Additional problems are that they can obviously only be used for examination of electrically conducting materials and the efficiency of ultrasound generation and detection rapidly decreases with lift-off distance between the EMAT face and the surface of the test object as well as with increasing temperature of the test object. Laser beam ultrasound generation and detection overcomes all of these problems and affords the opportunity to make truly non-contact ultrasonic measurements in both electrically conducting and non-conducting materials, in materials at elevated temperatures, in corrosive and other hostile environments, in geometrically difficult to reach locations, in outer space, and do all of this at relatively large distances, 1.e. meters, from the test object surface.

\section{LASER BEAM ULTRASOUND GENERATION}

As early as 1963, White (ref. 12) reported the generation of elastic waves in solid materials by transient surface heating and research has continued in this area up to the present time (refs. 13-22). Three different mechanisms have been proposed to account for the generation of ultrasonic waves by the impact of pulsed laser beams, namely radiation pressure, ablation, and thermoelasticity. Radiation pressure, which is caused by momentum transfer from the incident electromagnetic pulse, is the least efficient of the three proposed 
mechanisms and is therefore of little importance for practical applications. At the other extreme, when a laser pulse possessing sufficient power density strikes the surface of a material the electromagnetic radiation is absorbed in a very thin layer of the material and vaporizes it. The amplitude of the ultrasonic wave generated in the material by this ablation process can of ten be increased by placing a proper coating of different thermal properties on the surface of the test object. Although the surface of the test object is slightly damaged when ablation occurs, in certain cases the amount of damage is acceptable when such a generation process is the only way to obtain ultrasonic waves of sufficient amplitude in a non-contact manner. The thermoelastic process consists of absorption of a laser pulse possessing moderate energy in a finite depth of the material under investigation such that thermal expansion causes a volume change and consequently an elastic wave. Thus, the thermoelastic process is the only process which is truly nondestructive and still capable of generating an ultrasonic wave of sufficient amplitude for nondestructive evaluation purposes.

\section{LASER GENERATION PIEZOELECTRIC DETECTION}

Initial work with laser generation of ultrasound was performed using piezoelectric transducers as detectors since the various investigators had prior experience with this type of transducer and associated electronic equipment. Figure 7, (ref. 21), shows an example of an ultrasonic waveform generated by a Q-switched Nd:YAG pulsed laser in a graphite-epoxy composite laminate. As shown, the laser pulse was incident normal to the laminate plies and the resulting waveform was detected by a plezoelectric transducer mounted on the opposite side of the specimen. It should be noted that even though the laser energy delivered to the specimen generated an ultrasonic pulse of sufficient amplitude to undergo multiple reflections through the specimen, absolutely no damage was done to the specimen surface by the laser beam.

\section{LASER BEAM INTERFEROMETRIC ULTRASOUND DETECTORS}

A number of investigators have used laser beam interferometers for noncontact detection of acoustic emission and ultrasonic waves in solid materials (refs. 13, 15-17, 19-25). Figure 8 is a schematic diagram of one of the most sensitive broadband laser interferometric detectors of acoustic waveforms constructed to date (ref. 26). This device is a modified Michelson interferometer which includes active stabilization of the relative optical path lengths of the signal and reference arms of the interferometer. It possesses a flat frequency response from $D C$ to $60 \mathrm{MHz}$ and drops of to the $3 \mathrm{~dB}$ point at 160 $\mathrm{MHz}$. Since the detection signal-to-noise ratio is inversely proportional to the square root of the detection bandwidth, increasing the bandwidth can degrade detection of small amplitude signals. The use of balanced photodiodes as optical detectors and an improved laser power supply has permitted detection of signals with amplitudes as small as $0.1 \mathrm{~nm}$ ( 1 Angstrom) while retaining detection bandwidth. The use of beam steering mirrors, along with a telescoping lens assembly to focus the signal component of the laser beam on the specimen surface, makes adjustment of the interferometer very convenient. It can also 
accomodate a wide range of orientations of the specimen surface major readjustment.

\section{LASER GENERATION LASER DETECTION OF ULTRASOUND}

Although a number of investigators have reported both generation and detection of ultrasonic waves in solld materials using laser beams, only two investigations have been conducted using low-power laser beams. This is especially important for many non-contact nondestructive evaluation applications where portability and power limitations are a necessity. In 1983, Dewhurst (ref. 17) constructed a hand-held laser generator of ultrasonic pulses based on components taken from a laser rangef inding device. A photograph of this laser generator is reproduced in Fig. 9. Operating at a wavelength of 1.06 microns, the hand-held laser has provided optical pulses on a single shot basis with energies of 3-10 millijoules in 10 nanoseconds. This optical output was sufficient to generate both surface and bulk ultrasonic waves with an aluminum specimen.

Most recently, Bourkoff and Palmer (ref. 20) have succeeded in generating ultrasonic pulses in metals and composite materials using a low-energy tunable dye laser emitting 6 nanosecond pulses with $20-210$ microjoule energies. The ultrasonic waveforms were detected optically with a modified in-line Fizeau calibrated laser interferometer having improved signal-to-noise ratio. The interferometer possesses improved fringe stability due to an electronic control system, which enables it to be operated near common low frequency noise sources. High frequency noise due to the interferometer laser source itself is also reduced. The overall sensitivity is about $50 \mathrm{pm}$ over a $10 \mathrm{MHz}$ bandwidth. Figures $10(a)$ and $10(b)$ show the system and detected waveforms, respectively. This work has shown that it is entirely feasible to use a portable laser generation laser detection system for non-contact characterization of composite materials. To the best of the present authors knowledge this is the first report of laser beam generation and detection of ultrasound in composite materials.

\section{HIGH-POWER ULTRASONIC WAVES}

In the event that the wave amplitude is increased to very large values, ultrasonic waves propagating through a metal specimen may cause the metal to deform plastically. The three mechanisms that have been proposed to account for this plastic deformation are superposition of the dynamic high-power ultrasonic stress on the quasi-static tensile stress, heating of the specimen due to the applied high-power ultrasound, and interaction of the high-power ultrasonic waves with dislocations in localized regions of the test specimens (ref. 27).

Figure 11 shows the results of an experiment which illustrates the influence of high-power ultrasound on the load-time curve of an aluminum crystal. The crystal was subjected to a continuous uniaxial tensile test, while intermittently insonating it with a high-power ultrasonic horn operating at 20 $\mathrm{kHz}$. Each load drop was produced by an $0.03 \mathrm{sec}$ insonation period at constant horn input power. The dashed curve drawn through the minimum loads attained during insonation corresponds with the load-time curve, or equivantly the 
stress-strain curve, that would have been obtained if the high-power ultrasound had been applied continuously during the tensile test.

In 1979, Mignogna and Green (ref. 29) developed a multiparameter experimental system which, for the first time, permitted simultaneous measurement of sufficient quantities to test all of the proposed mechanisms for the influence of high-power ultrasound on the mechanical properties of metal specimens. The various parameters which could be either controlled or measured during both tensile elongation and insonation of a variety of single crystal and polycrystalline metal specimens are applied tensile load, specimen elongation, contact pressure between high-power ultrasonic horn ( $20 \mathrm{kHz}$ ) and test specimen, electrical power supplied to the horn, high-power insonation time, test specimen surface temperature distribution, low-power ultrasonic ( $8 \mathrm{MHz}$ ) wave velocity (directly related to elastic moduli) and attenuation (directly related to dislocation motion). A schematic diagram of the high-power ultrasonic horn assembly, specimen, gripping system, low-power nondestructive ultrasonic transducer, linear variable differential transformer, and support cage are shown in Fig. 12.

Figure 13 shows a set of typical data obtained from an aluminum single crystal specimen subjected to high-power insonation at $20 \mathrm{kHz}$, but not subjected to any tensile load. The insonation was applied at a constant power level for different time periods: $I=0.03 \mathrm{sec}$, II $=0.63 \mathrm{sec}$, III $=1.23 \mathrm{sec}$, IV $=1.83$ sec, $V=2.43 \mathrm{sec}$, and VI $=3.63 \mathrm{sec}$. Depicted are change in specimen length, relative change in low-power nondestructive ultrasonic velocity and change in low-power ultrasonic attenuation as a function of time. The changes in low-power ultrasonic velocity indicate small changes in the elastic moduli during insonation. The changes in low-power ultrasonic attenuation indicate that high-power ultrasound is capable of causing large scale dislocation motion and the resulting plastic deformation.

The temperature of the test specimens was monitored in all of the early experiments by epoxying copper-constantan thermocouples to the central region of the specimen gauge length. Infrared thermovision scans of the test specimens' surfaces (ref. 30) revealed extremely rapid temperature increases at the point of attachment of thermocouples to the specimens' surfaces, which casts doubt on all past temperature measurements and which has undoubtedly led to misunderstanding about the mechanism responsible for the observed load drops.

High-power ultrasonic insonation induced localized heating at displacement nodes in brass, copper, steel, and polymer specimens of resonant lengths. Hot zones detected at saw-cuts, drilled holes, fatigue cracks, and grain boundaries, coupled with the high-power ultrasound caused bending of a large grain polycrystalline specimen subjected to insonation alone, the ultrasonic attenuation results, and scanning electron microscope observations of the specimens' fracture surfaces clearly indicate that high-power ultrasound can interact with material inhomogeneities many orders of magnitude smaller than the ultrasonic wavelengths. Of particular importance for the present paper is the fact that the similarity of the ultrasonic attenuation results, as shown in the lower portion of Fig. 13 and the lower left portion of Fig. 4, provide strong evidence for the ability of sufficiently large amplitude long wavelength ultrasound to physically move dislocations causing plastic deformation of the test specimens. 
$X$-ray diffraction topography is the generic name given to a number of experimental techniques which permit images to be recorded of crystal lattice defects located in the volume of single crystals as well as those located in the surface layers. Defects ranging in size from dislocations upward may be Imaged over large areas of relatively thick specimens. Although the images recorded by $x$-ray diffraction topography do not possess the high resolution obtainable with transmission electron microscopy, they may be recorded under normal atmospheric conditions with no special specimen preparation which is particularly important for nondestructive evaluation of materials. Review articles describing x-ray diffraction topographic techniques may be found in references 31 and 32.

In 1976, Boettinger el al. (ref. 33) described a crystal topographic (ACT) system, which utilized the Bragg diffraction condition to obtain an expanded, highly collimated, monochromatic $x-r a y$ beam. Among the advantages of this expanded beam system are superior sensitivity to lattice imperfection induced strain fields. A portable $x$-ray image intensifier detector was routinely used to obtain rapid $x$-ray topographic images. A similar ACT system was constructed at Johns Hopkins and has been used to record $x$-ray back-reflection and transmission topographs of defect structure in a variety of metallic, semiconductor, and polymeric crystals.

In 1971, Green published a review paper (ref. 34) which described the design and performance characteristics of electro-optical systems for direct display of x-ray diffraction images. Subsequently, Green (ref. 35) in 1977 and Winter and Green (ref. 36) published other papers related to this subject. Figure 14 shows schematic drawings of one type of commonly used first generation portable $x$-ray image intensifier and a more recently developed second generation miniature $x$-ray image intensifier. These electro-optical systems have been used at Johns Hopkins to orient single crystals, to study crystal lattice rotation accompanying plastic deformation, to measure the rate of grain boundary migration during recrystallization annealing of cold-worked metals, to determine the physical state of exploding metals, to monitor the amorphous to crystalline phase transformation of rapidly solidified metals, to rapidly measure residual stress, to study the dynamics of structural phase transitions in ferroelectric crystals, and to record topographic images of lattice substructure and defects. An example, taken from the work of Chikawa (ref. 38), of the application of an electro-optical system to image dislocations in a silicon crystal is reproduced in Fig. 15.

Of primary importance to the present paper is the work of Itagaki (ref. 39) who used the Lang $x$-ray diffraction topographic method to study the vibratory motion of charged dislocations in single crystal ice caused by the application of an alternating electric field. The experimental system developed by Itagaki made it possible to distinguish the dislocations vibrating under the influence of the electric field as well as their amplitude and sign of their changes.

In 1979 a Synchrotron Topography Project (STP) was established with the goal of designing and constructing an x-ray topography station on the National Synchrotron Light Source (NSLS) at Brookhaven National Laboratory. This project 
has proceeded in cooperation with NSLS and the system has nearly been completed on beam line $\mathrm{X}-19$. A description of this fully dedicated synchrotron topography station is given in ref. 40. Combination of appropriate components of the multiparameter high-power ultrasonic system, described previously, with synchrotron $x$-ray diffraction topography, using $x$-ray image intensifier detectors coupled with solid state image digitizing television cameras and subsequent computerized signal processing ( $r$ ef. 36 ), affords the possibility of direct in situ observation of the interaction of ultrasonic waves with the microstructural and defect features of metallic, optically opaque ceramic and semiconductor materials for the first time.

\section{CONCLUSIONS}

Optimization of the use of ultrasonic techniques for nondestructive materials characterization has as a prerequisite a thorough understanding of the fundamental principles of the propagational characteristics of the ultrasonic waves in real materials. This understanding must take into account both linear and nonlinear elastic waves; quasi- and pure mode waves; energy flux deviations from the wave normals; attenuation due to absorption and scattering; mode conversion at bounding surfaces; and isotropic, anisotropic, homogeneous and inhomogeneous materials. Advances in this field will be made by the use of non-contact transducers particularly laser beam generation and detection systems. Combination of high-power ultrasound systems with synchrotron $x-r a y$ diffraction topography, using $x$-ray image intensifier detectors coupled with solid state image digitizing television cameras and subsequent computerized signal processing, affords the possibility of observing direct interaction of ultrasonic waves with the microstructure of real crystalline materials for the first time.

\section{REFERENCES}

1. Green, R.E., Jr., Ultrasonic Investigation of Mechanical Properties. Vol. III Treatise on Materials Science and Technology, Academic Press, New York (1973).

2. Merkulov, L.G. and Yakovlew, L.A., Propagation and Reflection of Ultrasonic Beams in Crystals, Akust. Zh. 8, 99-106 (1962) [Sov. Phys.-Acoust. 8, 72-77 (1962).

3. Henneke, E.G., II and Green, R.E., Jr., Light-Wave/Elastic-Wave Analogies in Crystals, J. Acoust. Soc. Amer. 45, 1367-1373 (1969).

4. Green, R.E. Jr., Effect of Metallic Microstructure on Ultrasonic Attenuation, in Nondestructive Evaluation:Microstructural Characterization and Reliability Strategies, 0. Buck and S.M. Wolf (eds.), The Metallurgical Society of AIME, Warrendale, PA, (1981) pp. 115-132. 
5. Swanson, R.A. and Green, R.E. Jr., Ultrasonic Attenuation Study of Dislocation Motion Part II. Experimental, Trans. Metallurgical Soc. AIME 230, 1390-1394 (1964).

6. Sachse, W. and Green, R.E. Jr., Experimental Study of the Orientation Dependence of Dislocation Damping in Aluminum Crystals, Trans. Metallurgical Soc. AIME 242, 2185-2190 (1968).

7. Joshi, N.R. and Green, R.E. Jr., Ultrasonic Detection of Fatigue Damage, Engr. Fract. Mech. 4, 577-583 (1972).

8. Hughes, D.S. and Kelly, J.L., Second-Order Elastic Deformation of Solids, Fhys. Rev. 92, 1145-1149 (1953).

9. Allen, D.R., Cooper, W.H.B., Sayers, C.M. and Silk, M.G. The Use of Ultrasonics to Measure Residual Stresses, in Vol. VI Research Techniques in Nondestructive Testing, R.S. Sharpe (ed.), Academic Press, Orlando, FLA, (1983) pp. 151-209.

10. Pao, Y-H, Sachse, W. and Fukuoka, H., Acoustoelasticity and Ultrasonic Measurements of Residual Stresses, in Vol XVII Physical Acoustics, W.P. Mason and R.N. Thurston (eds.), Academic Press, Orlando, FLA, (1984) pp. 61-143.

11. Liu, J., Mechanics Department, The Johns Hopkins Unfversity, Baltimore, MD (Unpublished Work).

12. White, R.M., Generation of Elastic Waves by Transient Surface Heating, J. Appl. Phys. 34, 3559-3567 (1963).

13. Bondarenko, A.N., Drobat, Yu. B., and Kruglov, S.V., Optical Excitation and Detection of Nanosecond Acoustic Pulses in Nondestructive Testing, Soviet J. NDT 12, 655-658 (1976).

14. Ledbetter, H.M. and Moulder, J.C., Laser-Induced Rayleigh Waves in Aluminum, J. Acoust. Soc. Amer. 65, 840-842 (1979).

15. Calder, C.A. and Wilcox, W.W., Non-Contact Materlal Testing Using Laser Energy Deposition and Interferometry, Mater. Eval. 38, 86-91 (1980).

16. Wellman, R.L., Laser System for the Detection of Flaws in Solids, Harry Diamond Laboratories, Report No. HDL-TR-1902 (1980).

17. Dewhurst, R.J., A Hand-Held Laser-Generator of Ultrasonic Pulses, NDT Communications 1, 93-103 (1983).

18. Rudd, M.J. and Doughty, J.A., Laser Generation of Ultrasound, Naval A1r Development Center, Report No. NADC-81067-60 (1983).

19. Alndow, A.M., Dewhurst, R.J., Palmer, S.B., and Scruby, C.B., Laser-Based Non-Destructive Testing Techniques for the Ultrasonic Characterization of Subsurface Flaws, NDT International 17, 329-335 (1984). 
20. Bourkoff, E. and Palmer, C.H., Low-Energy Optical Generation and Detection of Acoustic Pulses in Metals and Nonmetals, Appl. Phys. Lett. 46, 143-145 (1985).

21. Friant, C.L. and Green R.E., Jr., (Unpublished Work).

22. Rosen, M., Analytical Ultrasonics for Characterization of Metallurgical Microstructures and Transformations, (This Publication).

23. Palmer, C.H. and Green, R.E., Jr., Optical Detection of Acoustic Emission Waves, Appl. Opt. 16, 2333-2334 (1977).

24. Kline, R.A., Green, R.E., Jr., and Palmer, C.H., A Comparison of Optically and Piezoelectrically Sensed Acoustic Emission Signals, J. Acoust. Soc. Amer. 64, 1633-1639 (1978).

25. Palmer, C.H. and Green, R.E., Jr., Optical Probing of Acoustic Emission Waves, in Nondestructive Evaluation of Materials, J.J. Burke and V. Weiss (eds.), Plenum Publishing, New York (1979 pp.347-378.

26. Murphy, J.C. (Private Communication) Applied Physics Laboratory, The Johns Hopkins University, Laurel, MD 20707.

27. Green, R.E., Jr., Non-Linear Effects of High-Power Ultrasonics in Crystalline Solids, Ultrasonics, 13, 117-127 (1975).

28. Mignogna, R.B. and Green, R.E., Jr., Effects of High Frequency Loading on Materials, in Ultrasonic Eatigue, J.M. Wells, O. Buck, L.D. Roth, and J.K. Tien (eds.), Metallurgical Society of AIME, Warrendale, PA (1982) pp.63-85.

29. Mignogna, R.B. and Green, R.E., Jr., Multiparameter System for Investigation of the Effects of High-Power Ultrasound on Metals, Rev. Sci. Instrum. 5e, $1274-1277$ (1979).

30. Mignogna, R.B., Green, R.E., Jr., Duke, J.C., Jr., Henneke, E.G., II, and Reifsnider, K.L., Thermographic Investigation of High-Power Ultrasonic Heating in Materials, Ultrasonics 19, 159-163 (1981).

31. Armstrong, R.W, and Wu, C.C., X-ray Diffraction Microscopy, in Microstructural Analysis: Tools and Techniques, J.L. McCall and W.M. Mueller (eds.), Plenum Publishing, NY (1973) pp.169-219.

32. Tanner, B.K., X-ray Diffraction Topography, Pergamon Press, New York (1976).

33. Boettinger, W.J., Burdette, H.E., Kuriyama, M. and Green, R.E., Jr., Asymmetric Crystal Topographic Camera, Rev. Sci. Instrum. 47, 906-911 $(1976)$.

34. Green, R.E., Jr., Electro-Optical Systems for Dynamic Recording of X-ray Diffraction Images, in Advances in X-ray Analysis, C.S. Barrett, J.B. Newkirk, and C.0. Ruud (eds.), Vol.14, Plenum Press, NY (1971) pp.311-337.

35. Green, R.E., Jr., Direct Display of X-ray Topographic Images, in Advances in 
X-ray Analys1s, H.f. MoMurdie, C.S. Barrett, J.B. Newk1rk, and C.O. Ruud (eds.), Vol.20 Plenum Publishing, NY (1977) pp.221-235.

36. Winter, J.M. and Green, R.E., Rapid Imaging of X-ray Topographs, In Applications of $X$-ray Toposraphic Methods to Materials Sclence, $S$. Welssmann, F. Ballbar, and J.-F. Petroff (eds.), Plenum Publishing, NY (1984) pp. 45-58.

37. Rosemeler, R.G. and Green, R.E. Jr., A New Miniature Microchannel Plate X-ray Detector for Synchrotron Radiation, Nuclear Instrum. \& Methods 196, 299-301 (1982).

38. Chikawa, J., Fujimoto, I, and Abe, T., X-ray Topographic Observation of Moving Dislocations in Silicon Crystals, Appl. Phys. Lett. 21, 295-298 (1972).

39. Itagaki, K., X-ray Topographic Study of Vibrating Dislocations in Ice Under an AC Electric Field, in Advances in X-ray Analysis, Plenum Press, NY (1970) pp.526-538.

40. Bilello, J.C., Chen, H., Helo, A.B., Liu, J.M., Birnbaum, H.K., Herley, P.J. and Green, R.E., Jr., The Synchrotron Topography Project (STP) at the National Synchrotron Light Source, Nuclear Instrum. and Methods 215, 291-297 (1983). 


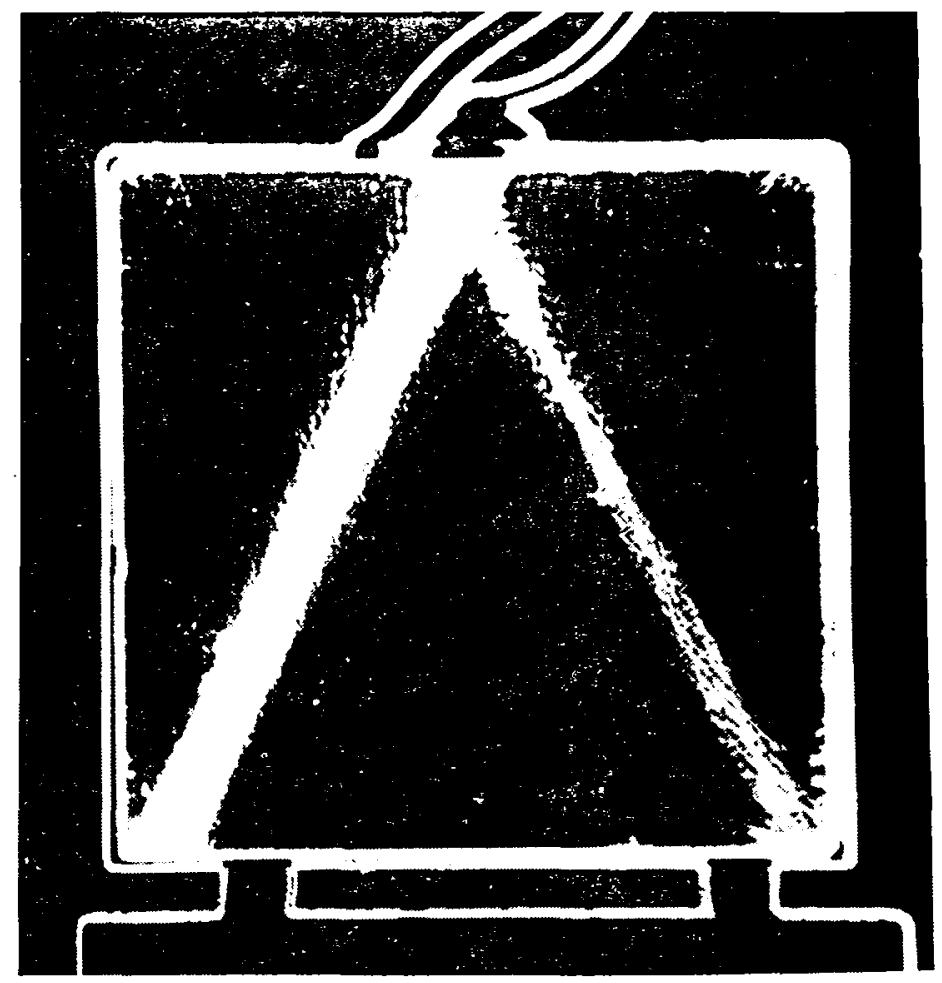

Figure 1. Schlieren photograph of ultrasound field associated with simultaneous generation of quasilongitudinal and quasi-shear waves in a quartz crystal from a single piezoelectric transducer [2]

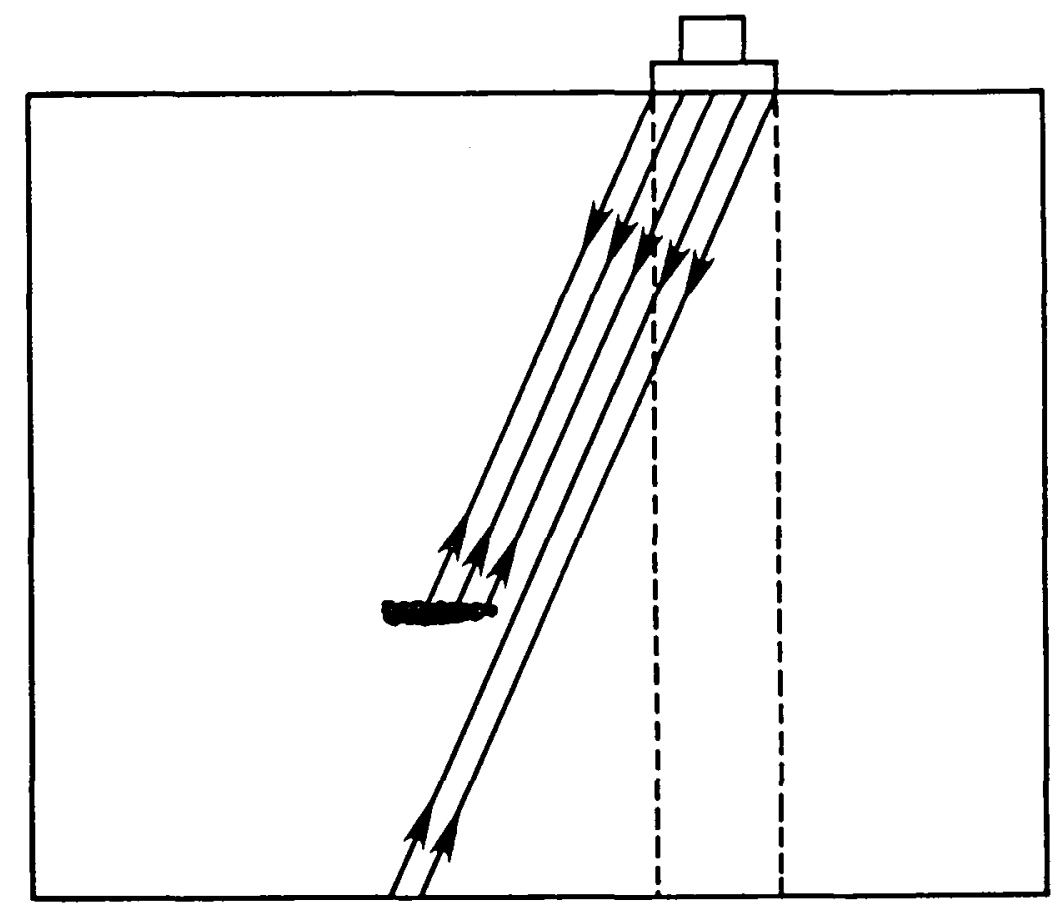

Figure 2. Schematic illustration of energy-flux deviation (refraction) causing misjudgement of crack location in anisotropic solid. 

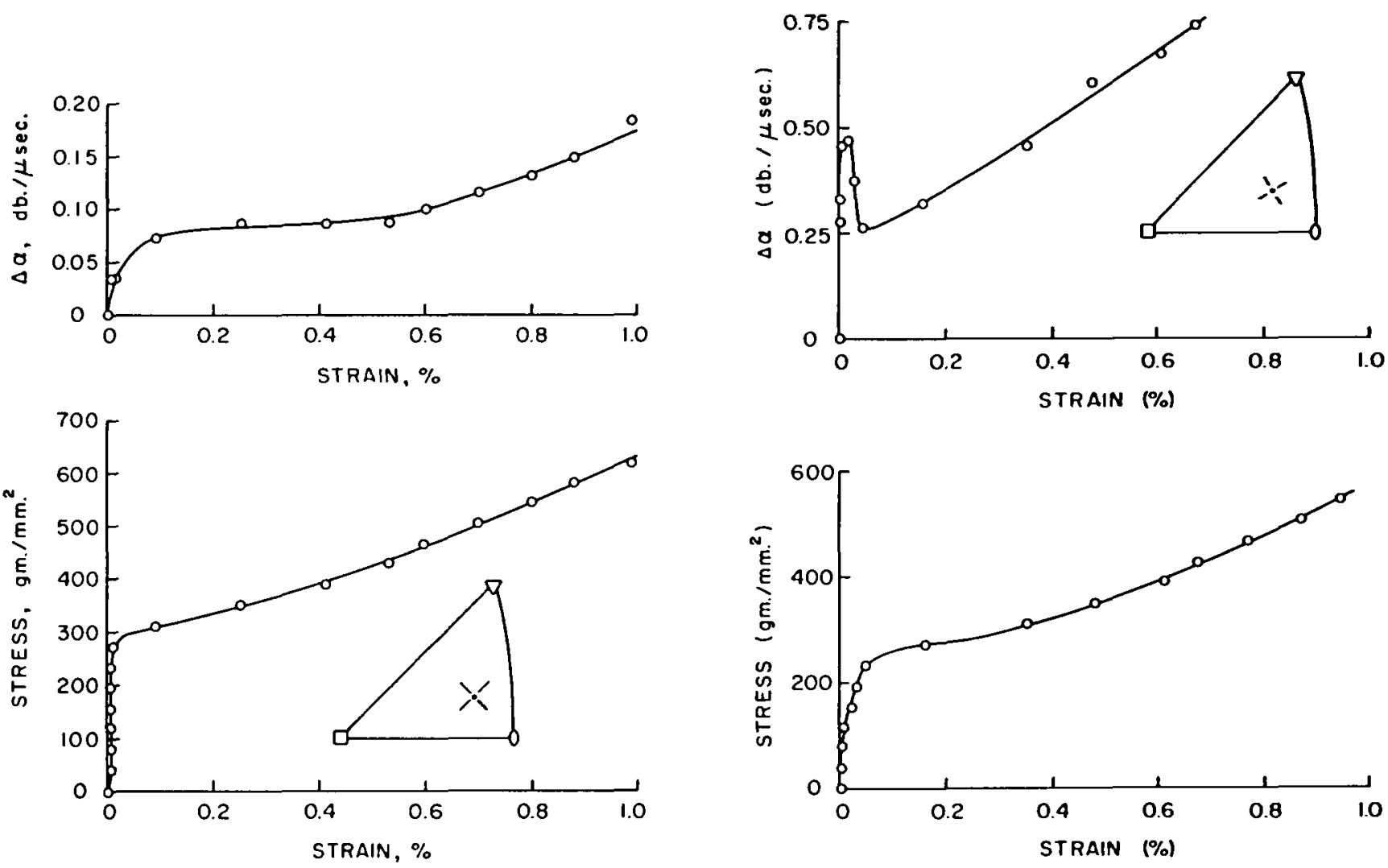

Figure 3. Stress and change in ultrasonic attenuation as a function of strain for quasi-shear waves polarized with large component of particle displacement (a) perpendicular and (b) parallel to projection of the primary-slip direction onto the end surface of the crystal specimen [5]. 


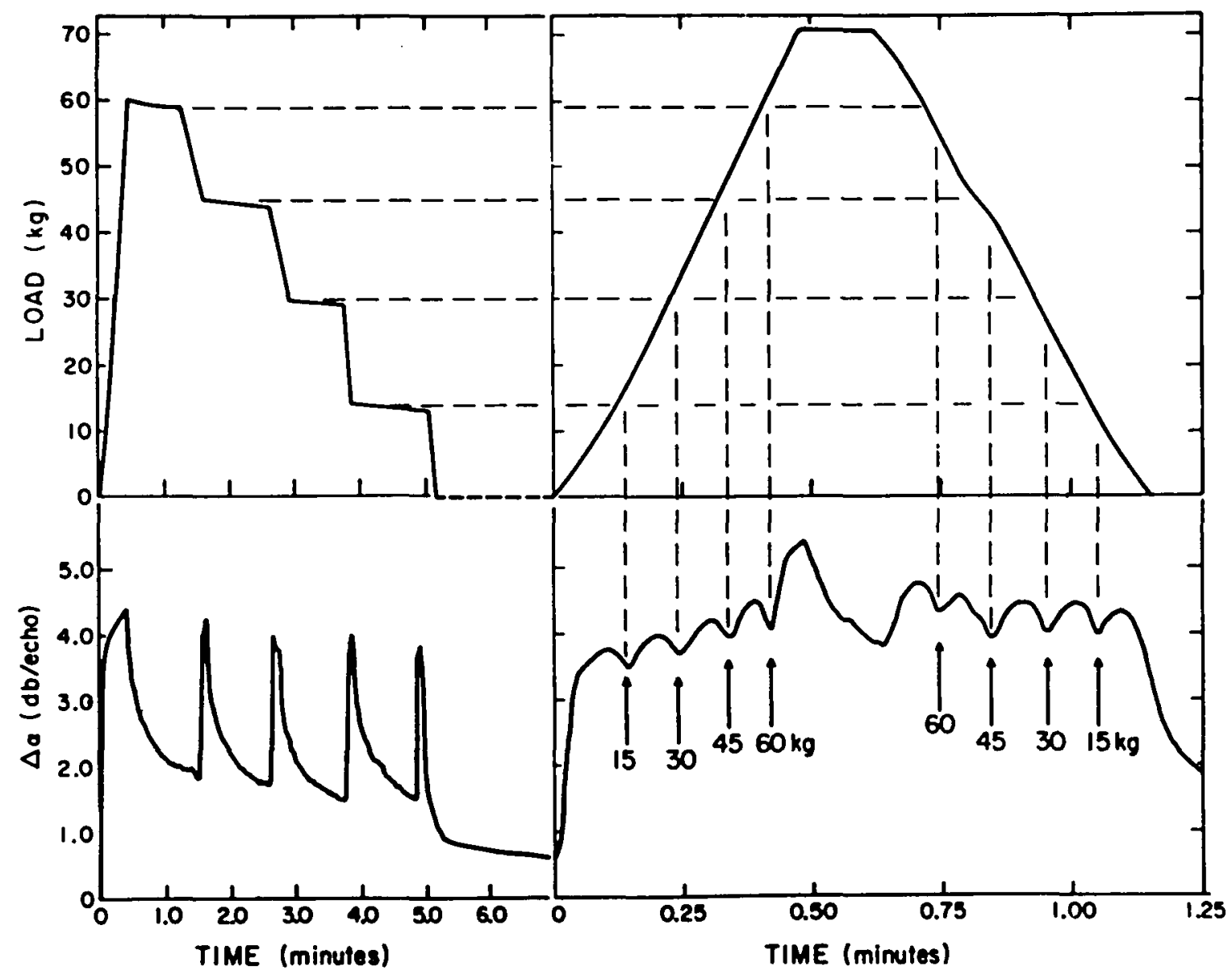

Figure 4. Load versus time and ultrasonic attenuation change versus time plots obtained during a loadhold-unload-hold sequence (left), followed by $a$ reload-unload sequence ( $r$ ight) conducted on an aluminum single crystal [6]. 


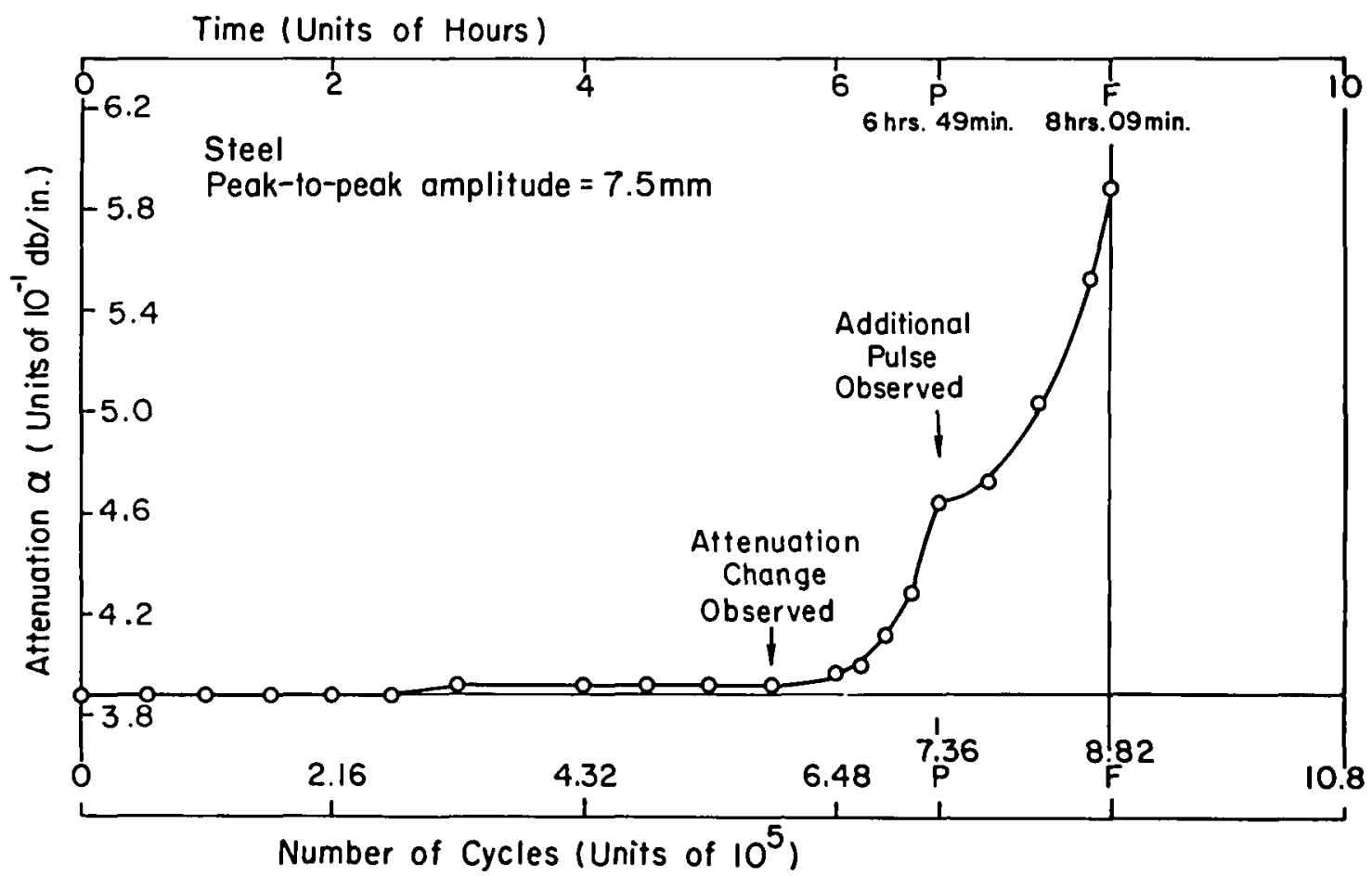

Figure 5. Longitudinal ultrasonic wave attenuation versus number of fatigue cycles for polycrystalline steel [7]. 


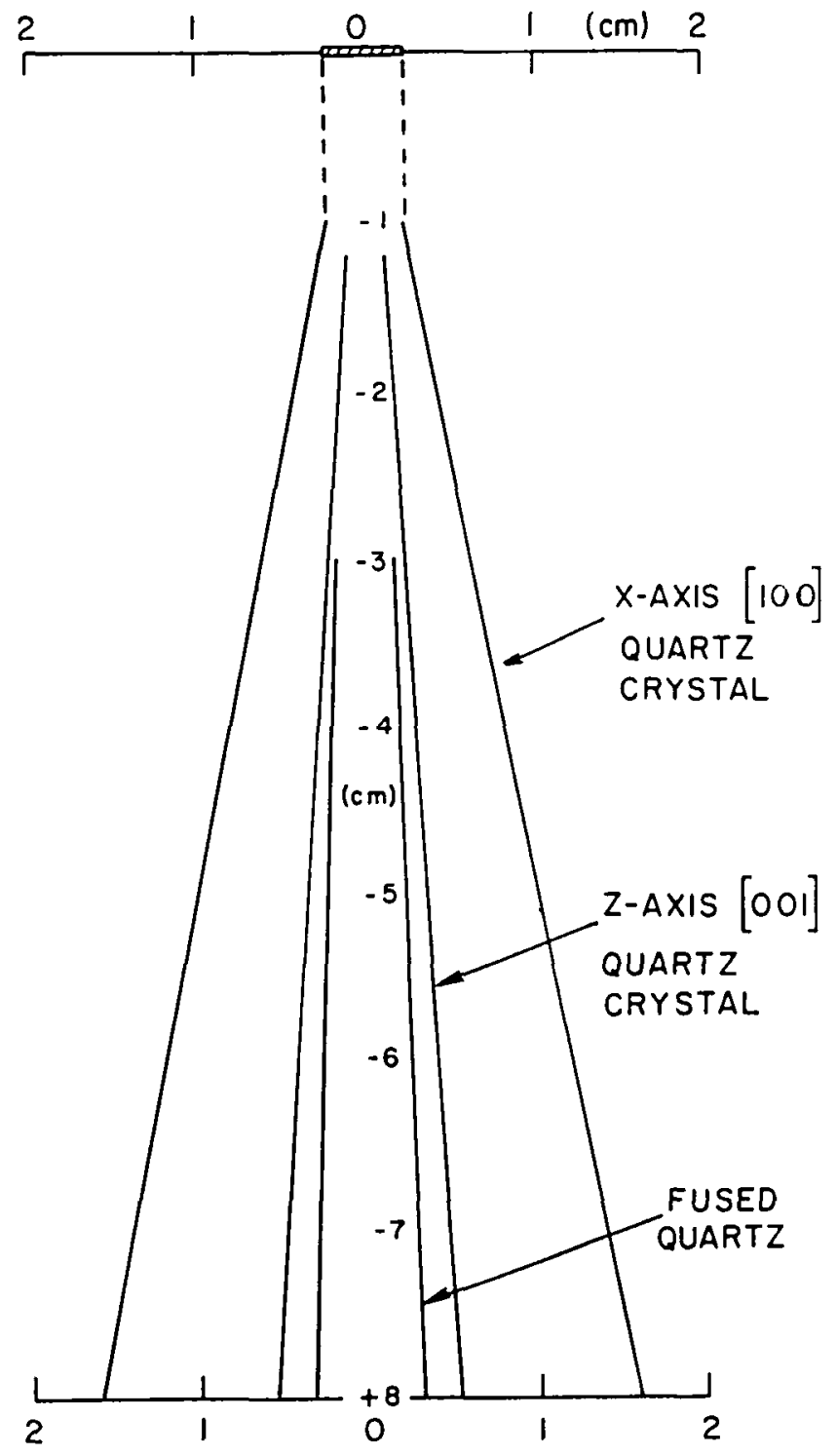

Figure 6. Dependence of diffraction spread of $10 \mathrm{MHz}$ longitudinal waves in quartz on anisotropy of propagation direction [11]. 

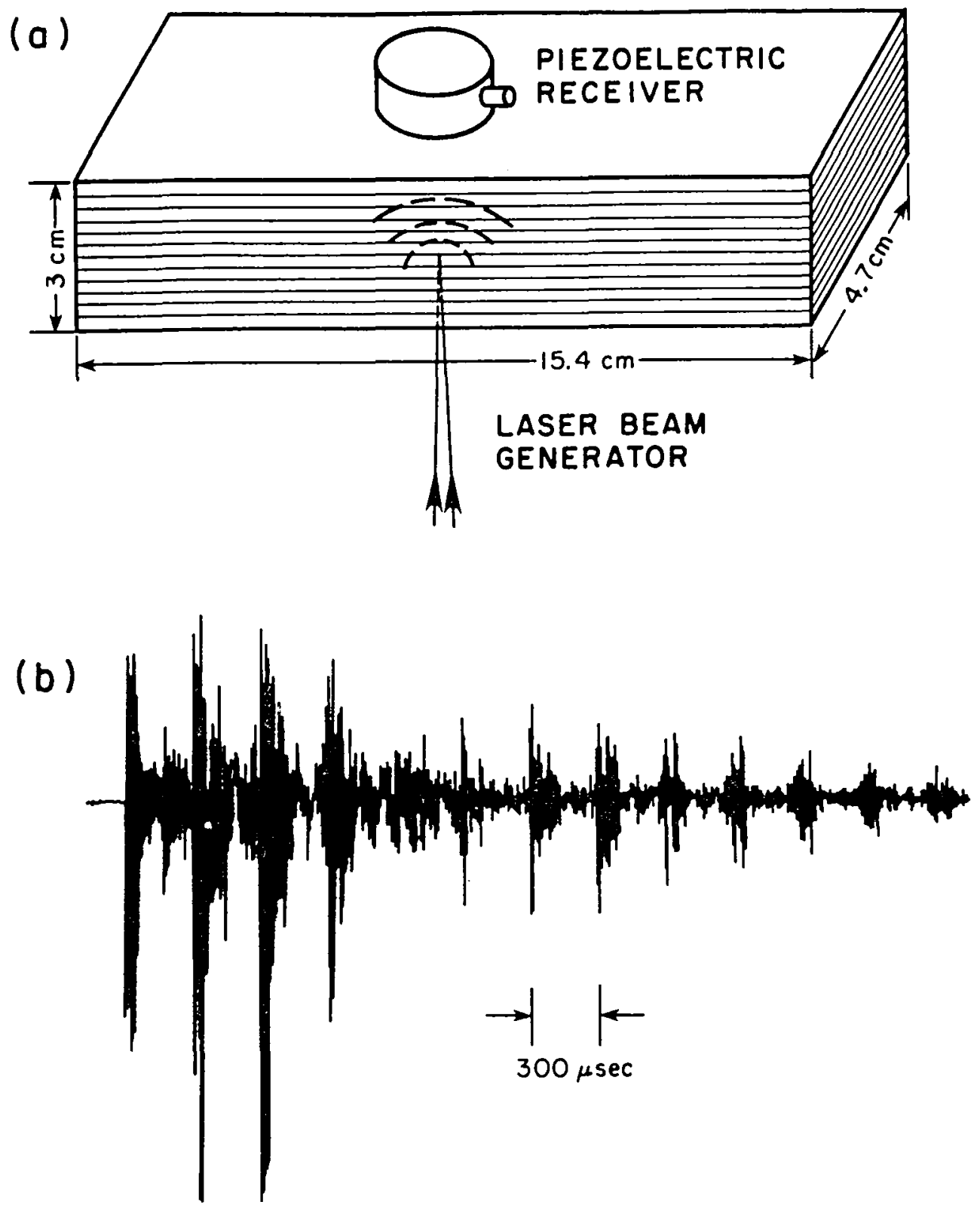

Figure 7. Laser generation of ultrasonic pulse in graphiteepoxy composite laminate [21].

(a) experimental configuration 


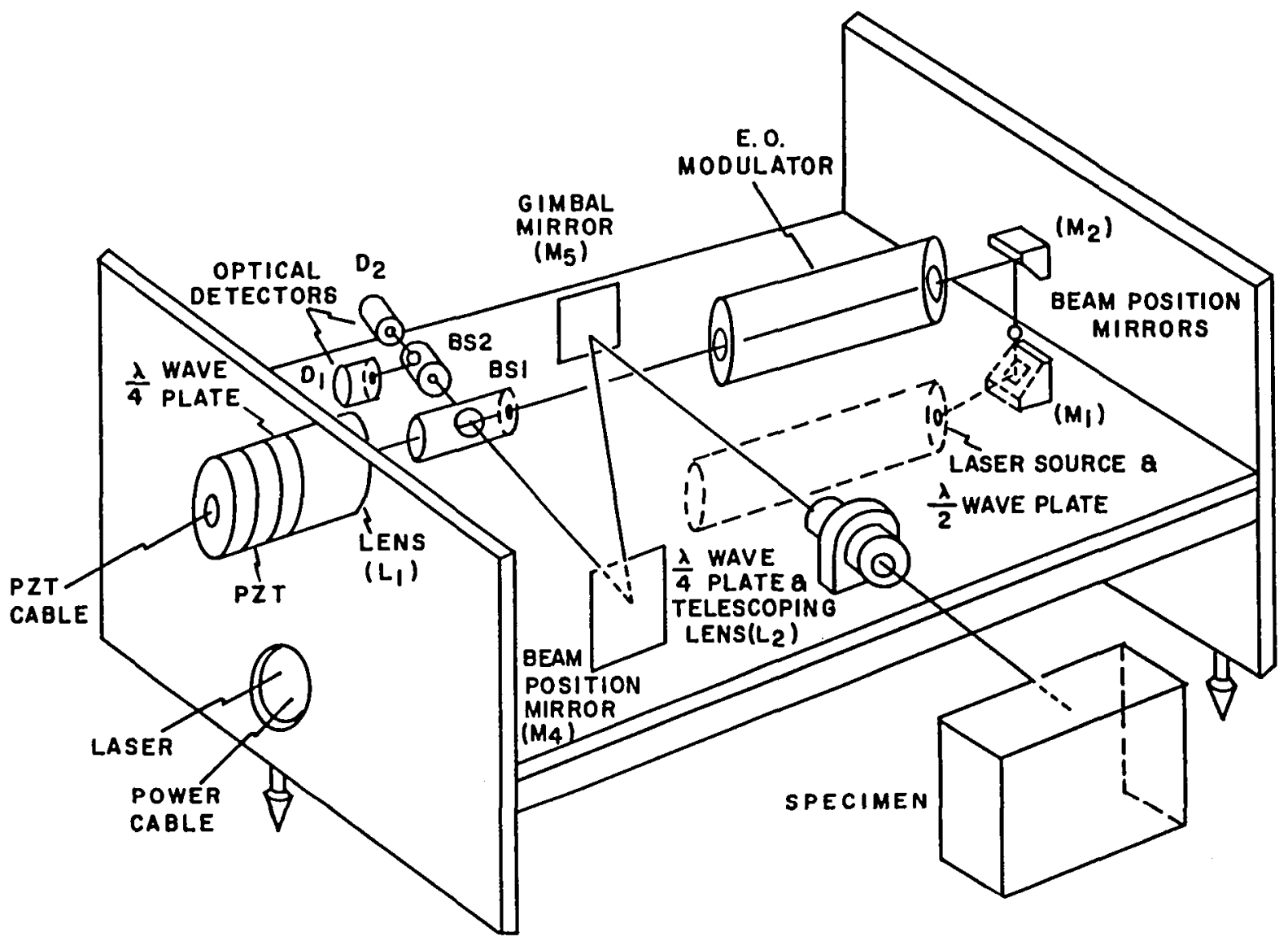

Figure 8. Schematic diagram of very sensitive broadband laser interferometer detection of acoustic waveforms [26]. 

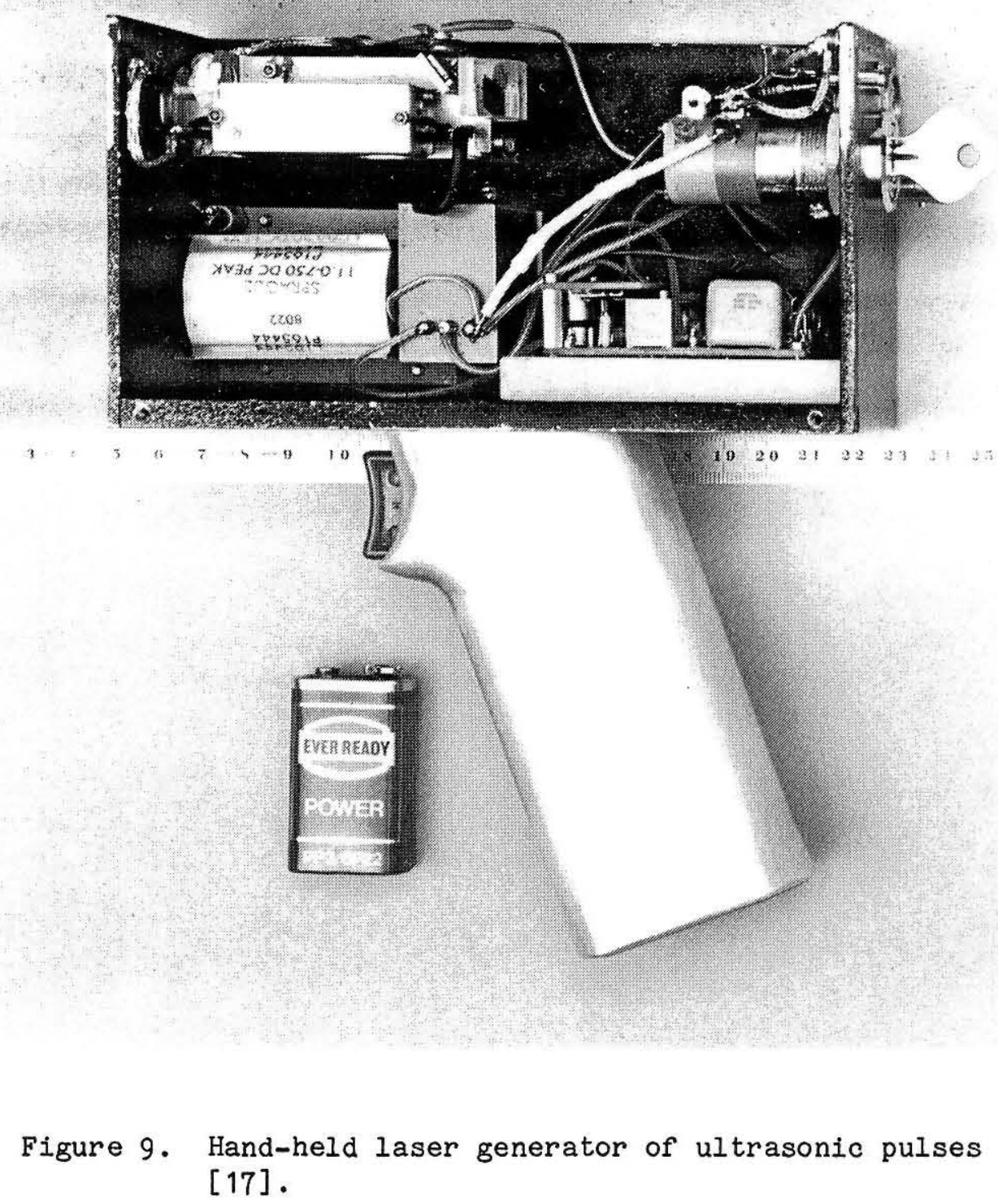

[17]. 

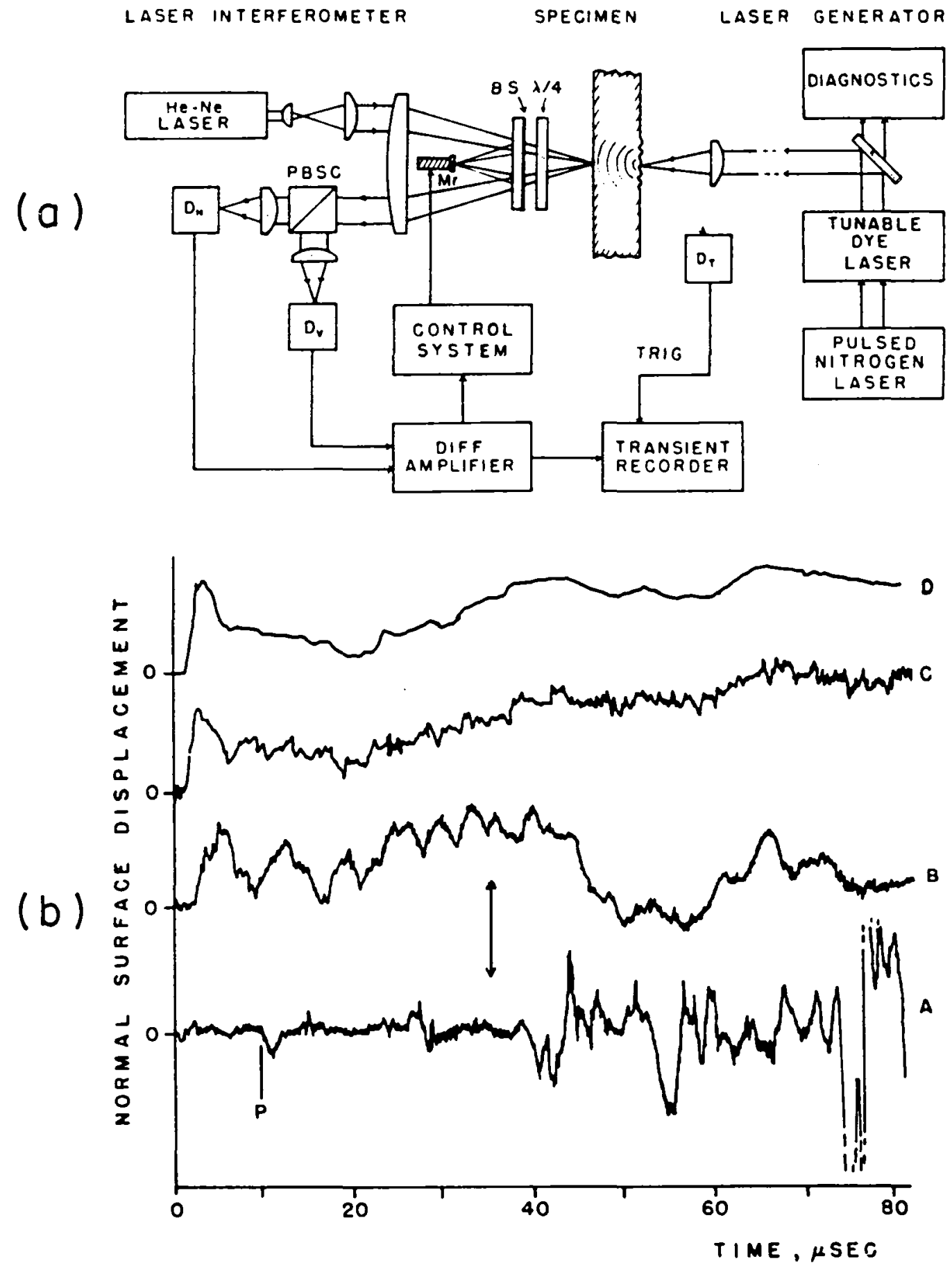

Figure 10. Low energy laser generation of ultrasonic pulses [20]

(a) interferometer system

(b) waveforms: A-6061-T6 uluminum, B-polyimideglass-fiber composite, $C$ and D-graphiteepoxy composite. 


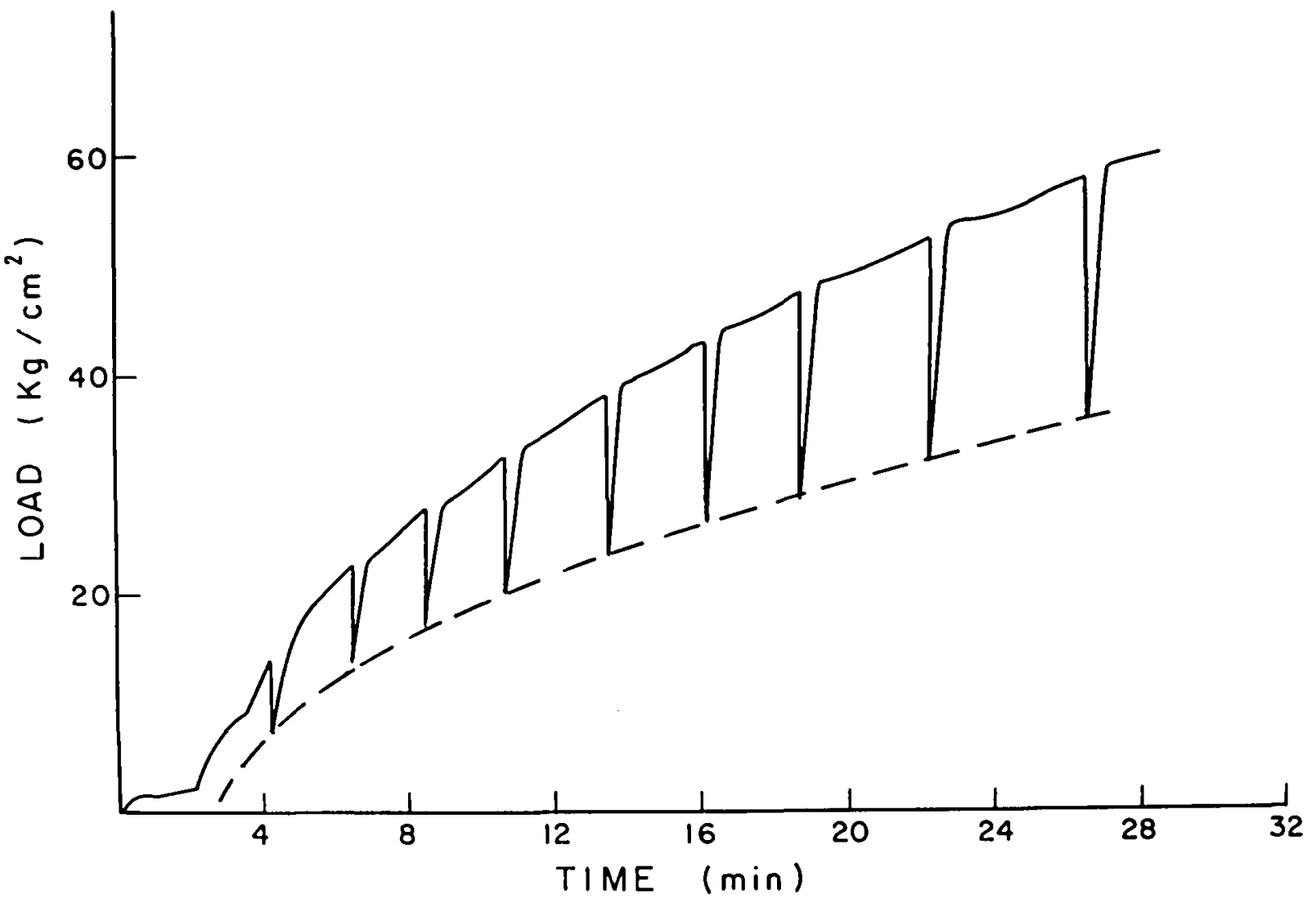

Figure 11. Load drops during tensile elongation of aluminum single crystal due to a sequence of $0.03 \mathrm{sec}$ insonation periods at the same high-power ultrasonic power level [28]. 


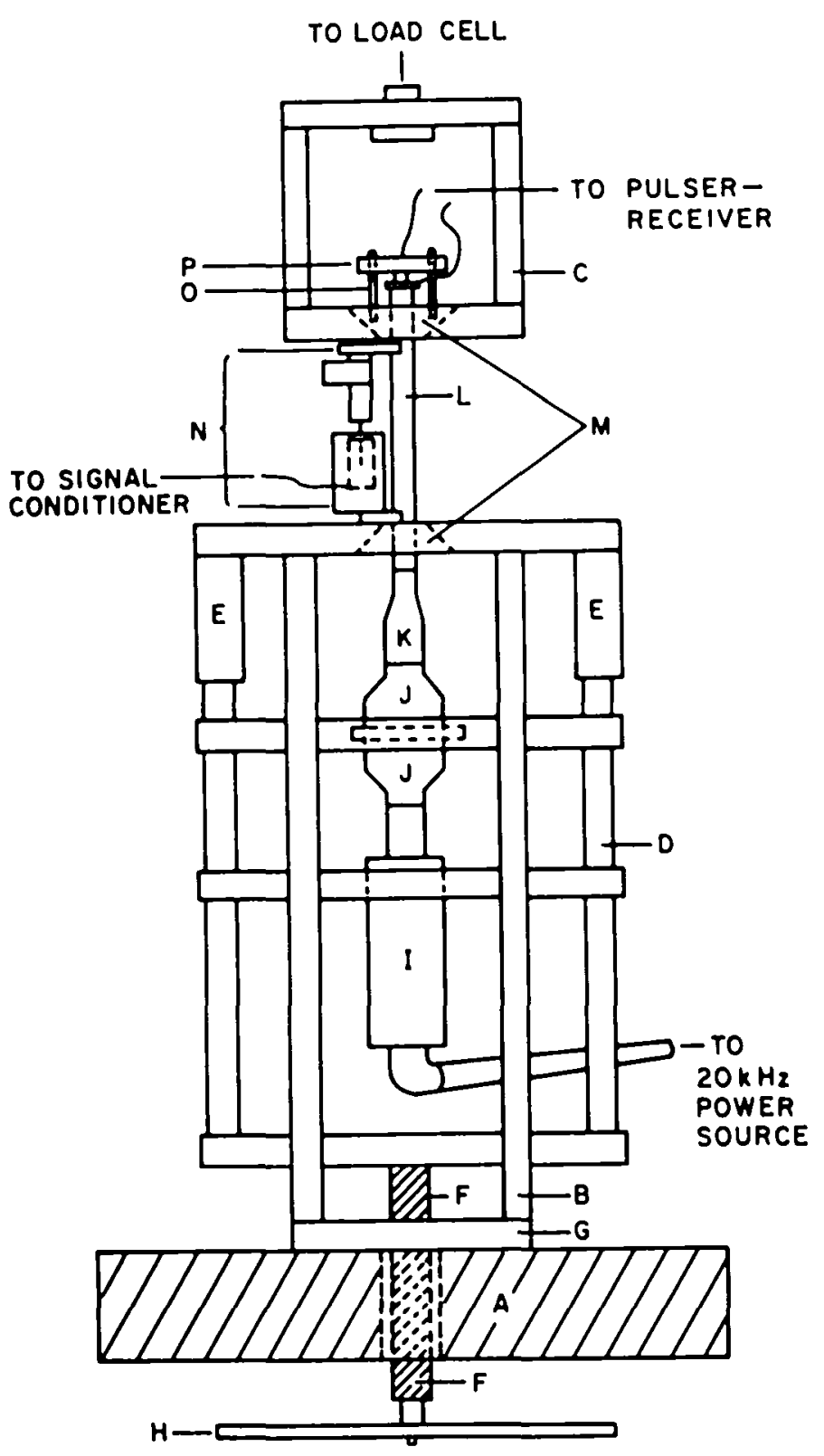

Figure 12. Schematic diagram of high-power ultrasonic horn assembly and test apparatus: A-moving crosshead; B-bottom grip cage; C-upper grip cage; D-mount for ultrasonic horn converter assembly; E-guide tubes; F-horn positioning screw; G-lower plate of bottom grip cage; H-pulley; I-converter; Jbooster; K-catenoidal horn; L-specimen; M-split contcal change; N-LVDT; $0-8 \mathrm{MHz}$ transducer, $\mathrm{P}-$ transducer holder [29]. 


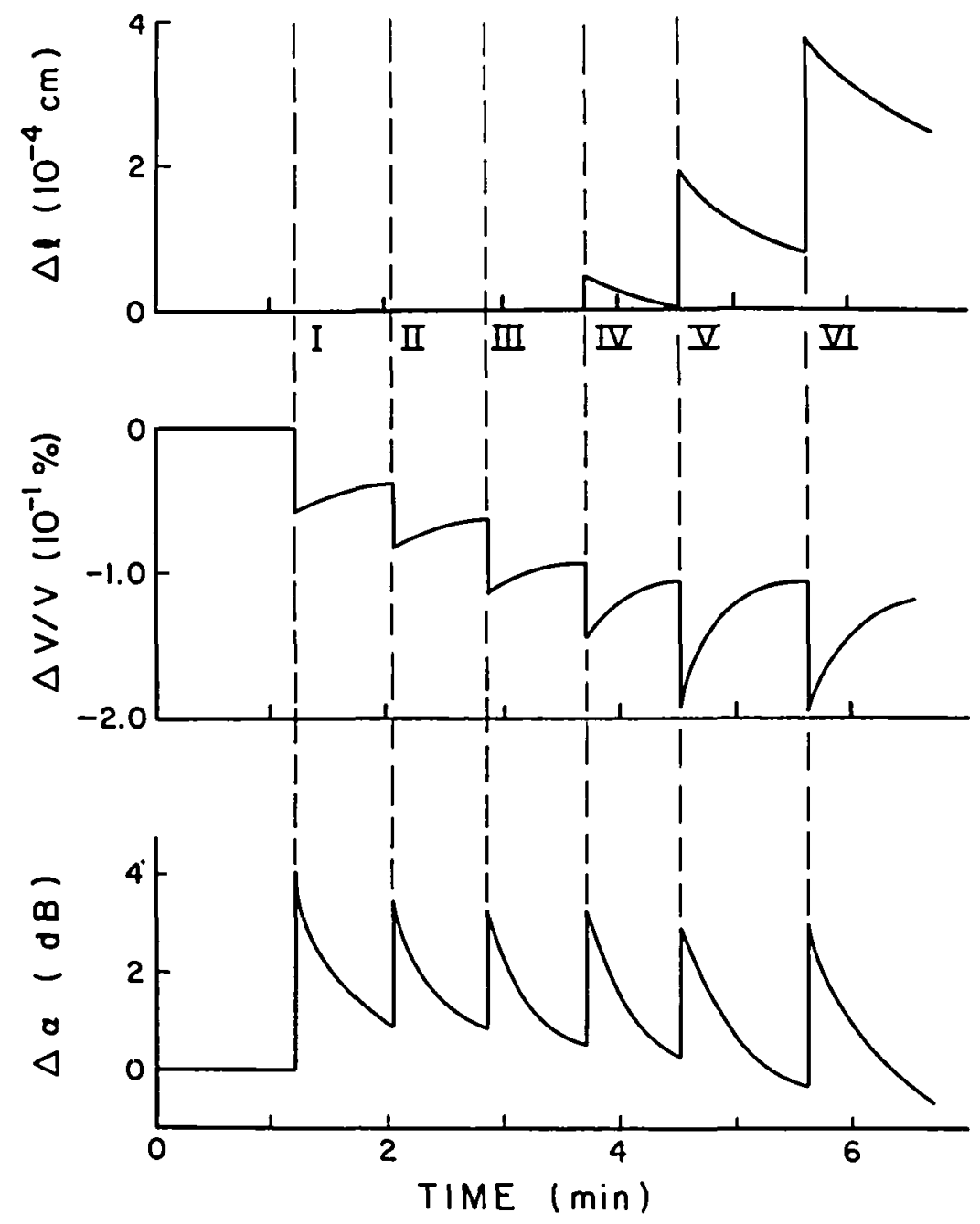

Figure 13. Data obtained from an aluminum single crystal subjected to high-power insonation only at a constant power level for different time periods [28]: $\quad$ I $=0.03 \mathrm{sec}$, II $=0.63 \mathrm{sec}$, III $=1.23$ $\mathrm{sec}, I V=1.83 \mathrm{sec}, V=2.43 \mathrm{sec}, V I=3.63 \mathrm{sec}$. $\Delta l=$ change in specimen length $\Delta v / v=$ relative change in ultrasonic velocity $\Delta \alpha=$ change in ultrasonic attenuation 


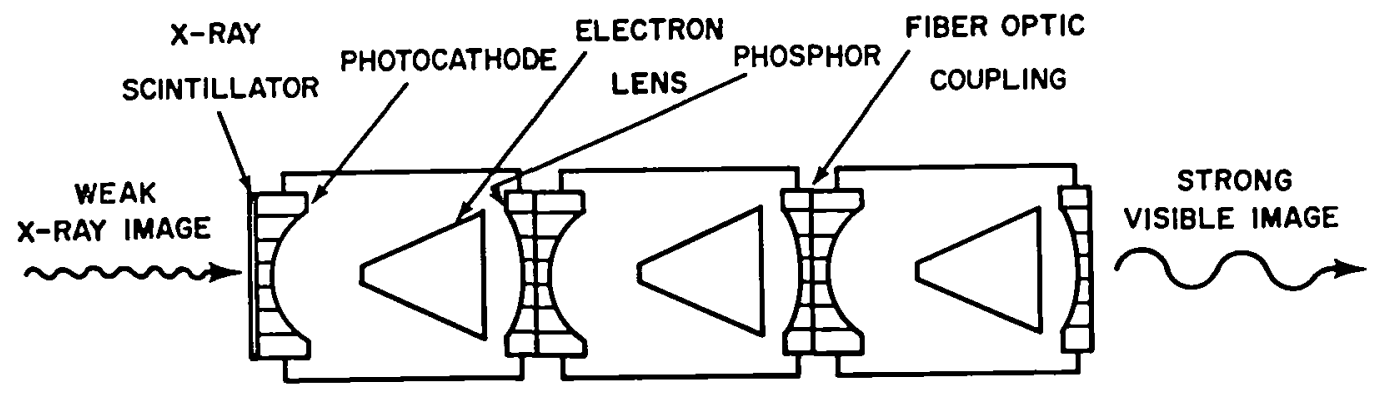

PORTABLE IMAGE X-RAY INTENSIFIER

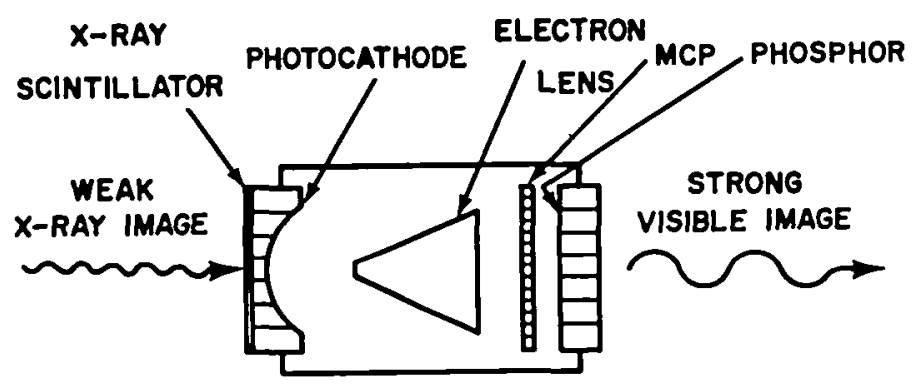

MINIATURE IMAGE X-RAY (MINIX) INTENSIFIER

Figure 14. Schematic drawings of first generation (upper) and second generation (lower) $x$-ray image intensifier tubes for rapid display of $x-r a y$ diffraction images [37]. 


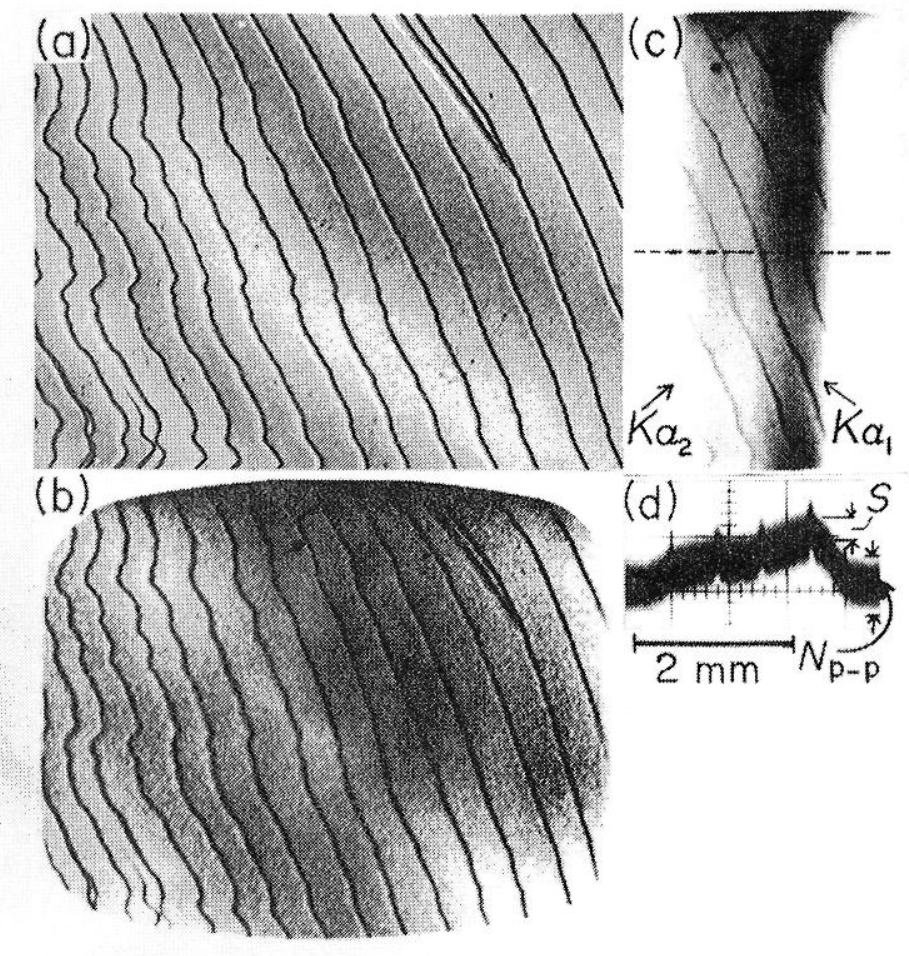

Figure 15. X-ray topographic images of static dislocations in a silicon crystal wafer [38]. (a) Scanning topograph recorded on nuclear emulsion plate (b) Video image of the same area. 